\title{
Predicting S-Wave Velocities for Unconsolidated Sediments at Low Effective Pressure
}

Scientific Investigations Report 2010-5138 



\section{Predicting S-Wave Velocities for Unconsolidated Sediments at Low Effective Pressure}

By Myung W. Lee

Scientific Investigations Report 2010-5138 


\title{
U.S. Department of the Interior \\ KEN SALAZAR, Secretary \\ U.S. Geological Survey \\ Marcia K. McNutt, Director
}

\section{U.S. Geological Survey, Reston, Virginia: 2010}

\author{
For more information on the USGS — the Federal source for science about the Earth, its natural and living resources, \\ natural hazards, and the environment, visit http://www.usgs.gov or call 1-888-ASK-USGS \\ For an overview of USGS information products, including maps, imagery, and publications, \\ visit http://www.usgs.gov/pubprod \\ To order this and other USGS information products, visit http://store.usgs.gov
}

\begin{abstract}
Any use of trade, product, or firm names is for descriptive purposes only and does not imply endorsement by the U.S. Government.

Although this report is in the public domain, permission must be secured from the individual copyright owners to reproduce any copyrighted materials contained within this report.
\end{abstract}

Suggested citation:

Lee, M.W., 2010, Predicting S-wave velocities for unconsolidated sediments at low effective pressure: U.S. Geological Survey Scientific Investigations Report 2010-5138, 13 p. 


\section{Contents}

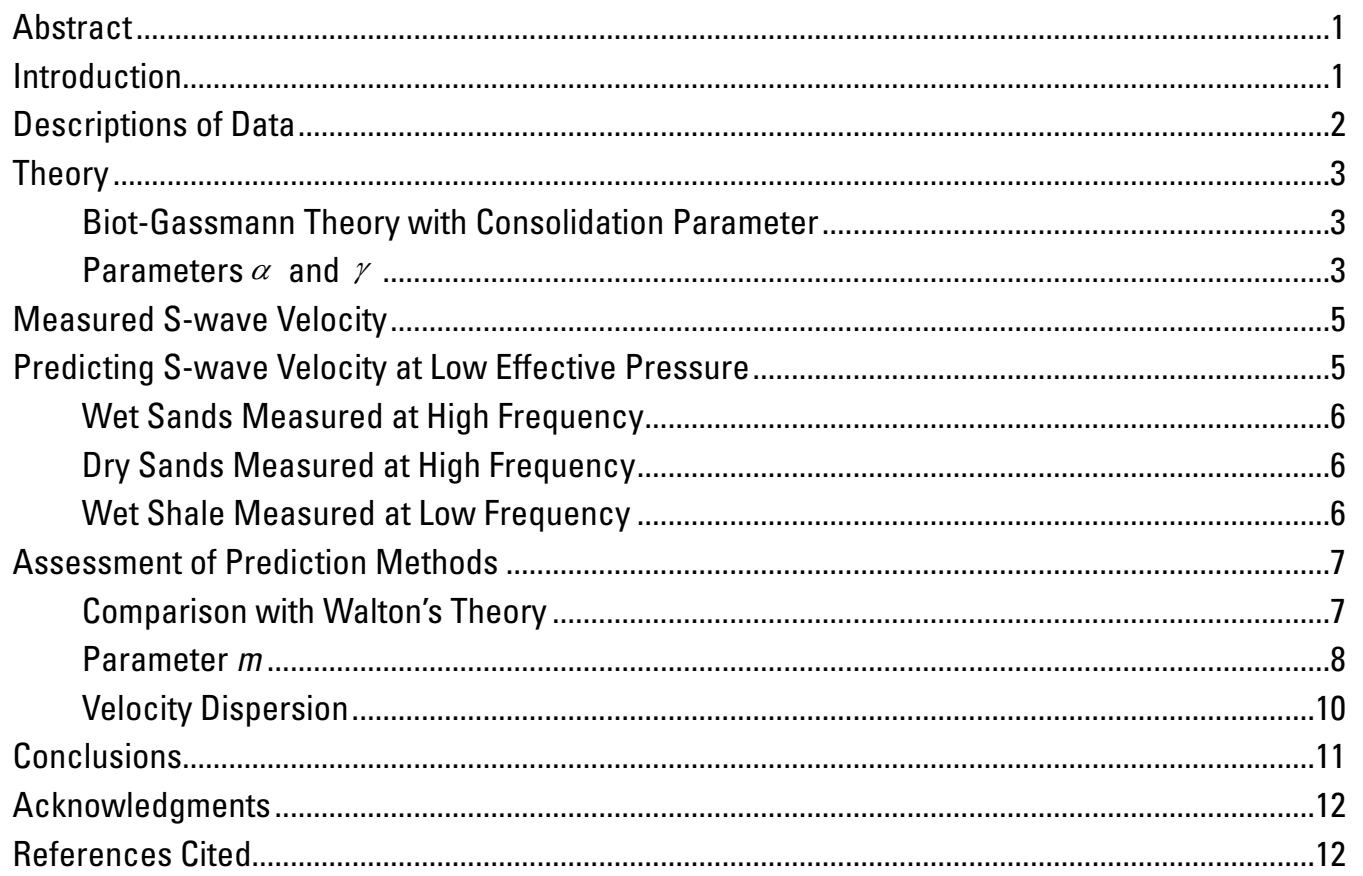

\section{Figures}

1. Location map of sites drilled during the Joint Industry Project Leg II Expedition.............2

2. Measured velocities for the Gulf of Mexico sands ...............................................................

3. Estimated parameters from velocities and porosities......................................................

4. Relation between $\mathrm{P}$-wave and $\mathrm{S}$-wave velocities from various sources .........................5

5. Measured and predicted S-wave velocities for Gulf of Mexico and

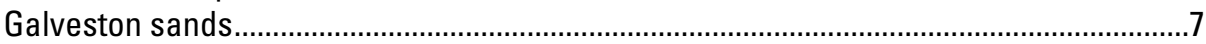

6. Measured and predicted S-wave velocities for dry sands ................................................8

7. Well-log measured and predicted S-wave velocities at the Gulf of Mexico......................

8. Measured velocities of Gulf of Mexico sands and predicted velocities using the Walton's equation.................................................................................................. 10

9. Difference between measured and predicted velocities of Gulf of Mexico sands.........11 



\title{
Predicting S-Wave Velocities for Unconsolidated Sediment at Low Effective Pressure
}

\author{
By Myung W. Lee
}

\section{Abstract}

Accurate S-wave velocities for shallow sediments are important in performing a reliable elastic inversion for gas hydrate-bearing sediments and in evaluating velocity models for predicting $\mathrm{S}$-wave velocities, but few $\mathrm{S}$-wave velocities are measured at low effective pressure. Predicting S-wave velocities by using conventional methods based on the BiotGassmann theory appears to be inaccurate for laboratorymeasured velocities at effective pressures less than about 4-5 megapascals (MPa). Measured laboratory and well log velocities show two distinct trends for S-wave velocities with respect to P-wave velocity: one for the S-wave velocity less than about 0.6 kilometer per second $(\mathrm{km} / \mathrm{s})$ which approximately corresponds to effective pressure of about 4-5 MPa, and the other for $\mathrm{S}$-wave velocities greater than $0.6 \mathrm{~km} / \mathrm{s}$. To accurately predict $\mathrm{S}$-wave velocities at low effective pressure less than about 4-5 MPa, a pressure-dependent parameter that relates the consolidation parameter to shear modulus of the sediments at low effective pressure is proposed. The proposed method in predicting S-wave velocity at low effective pressure worked well for velocities of water-saturated sands measured in the laboratory. However, this method underestimates the well-log S-wave velocities measured in the Gulf of Mexico, whereas the conventional method performs well for the well $\log$ velocities. The P-wave velocity dispersion due to fluid in the pore spaces, which is more pronounced at high frequency with low effective pressures less than about $4 \mathrm{MPa}$, is probably a cause for this discrepancy.

\section{Introduction}

Gas hydrate, an icelike compound of natural gas and water, is widespread in the Gulf of Mexico (GOM) (Milkov and Sassen, 2001), particularly on the continental slope with water depths in the range of 540-2,000 meters (m). One of the objectives of the GOM first Joint Industry Project (JIP Leg I) is the development of seismic analysis methods pertinent to gas hydrate-bearing sediments (GHBS). For the inversion of elastic impedances to estimate gas hydrate saturations, the use of predicted S-wave velocity in the absence of measured S-wave velocity increases the accuracy of the elastic inversion (Lee, 2006a). However, most theories predicting S-wave velocities work well for sediments at high effective pressure, possibly greater than 4-5 megapascals (MPa) (for example, Greenberg and Castagna, 1992; Xu and White, 1996; Jørstad and others, 1999; Lee, 2006b, 2006c). Although there are existing theories applicable to shallow sediments (for example, Walton, 1987; Dvorkin and others, 1999; Lee, 2002), measurements of S-wave velocities at low effective pressure and at the seismic and logging frequencies are lacking to test their effectiveness.

During field testing of phase II of the JIP Leg I, drilling, coring, and logging were conducted to test, validate, and adjust various models developed during the phase I program. Two field sites were selected (fig. 1): one at Atwater Valley (AT13) and the other at Keathley Canyon (KC151). Lee and others (2008) measured mechanical and electromagnetic properties of recovered sediments at the two sites in order to gain insight into processes accompanying nucleation and growth of gas hydrate, and also measured S-wave velocities at the effective pressures less than about $2.5 \mathrm{MPa}$.

In 2009, the JIP conducted its Leg II (JIP Leg II) loggingwhile-drilling (LWD) operations at three sites (Walker Ridge, Green Canyon, and Alaminos Canyon) in the northern GOM (fig. 1). These locations were identified, primarily from the 3-D seismic data, to test geological and geophysical interpretation methods to prospect for gas hydrate-bearing sand reservoirs (Hutchinson and others, 2009; Shedd and others, 2009). A primary scientific objective of the drilling was to collect high-quality LWD data to further refine estimates of gas hydrate saturations (Boswell and others, 2009). During this expedition, a suite of LWD well logs, including S-wave velocities at shallow depths, were acquired.

The purpose of this investigation is to determine whether the overestimation of S-wave velocity is due to (1) the inaccuracy of the rock physics model based on the Biot-Gassmann theory (BGT) at low effective pressure, or (2) other causes such as velocity dispersion, which is more pronounced at low effective pressure with high-frequency measurement. If the overestimation of S-wave velocity is due to the velocity dispersion, conventional BGT-based methods can be used 


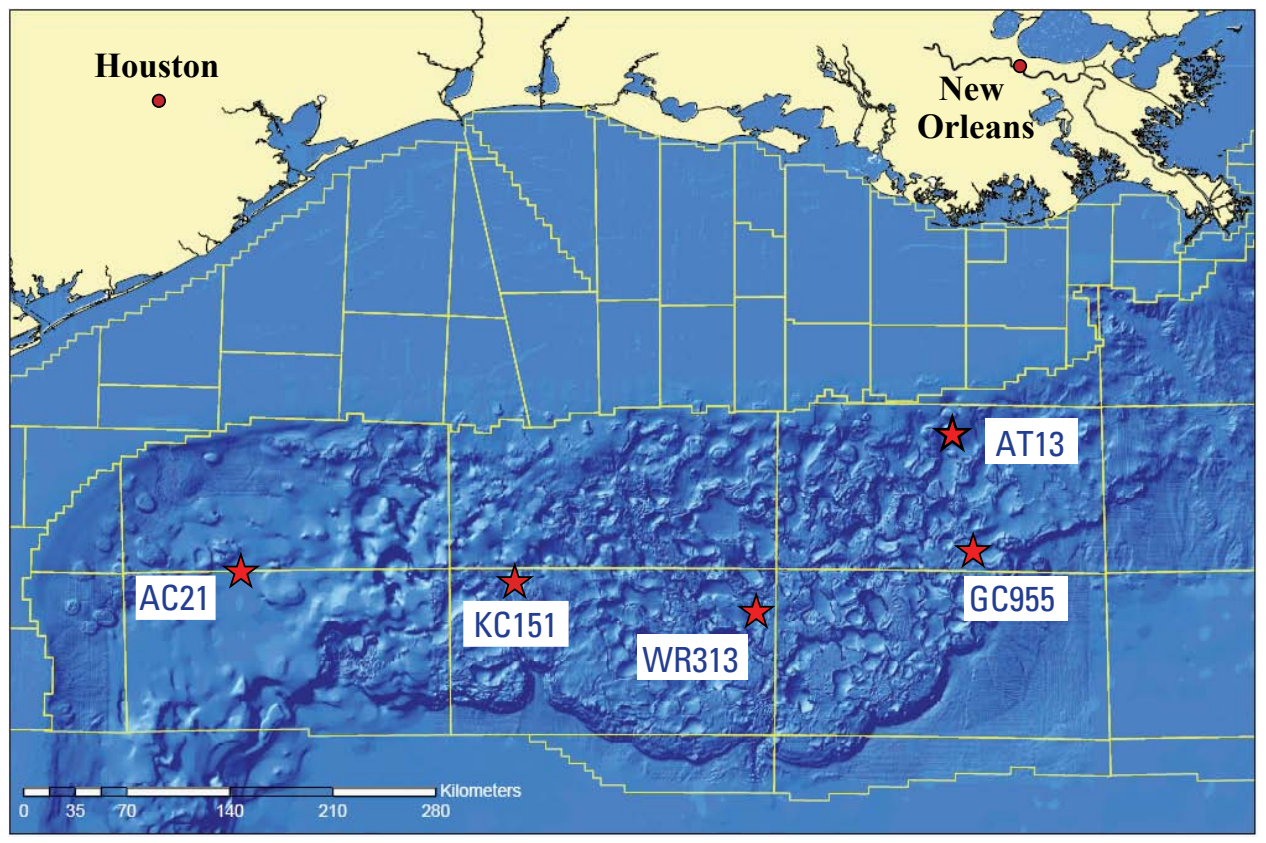

Figure 1. Location map of sites drilled during the Joint Industry Project Leg II Expedition and KC151 site, Gulf of Mexico (modified from Boswell and others, 2009).

by either accounting for the velocity dispersion or by using velocities measured at low frequencies such as well log (1-60 kilohertz [Hz]) and seismic (less than $100 \mathrm{~Hz}$ ) velocities. If the overestimation is due to inaccuracy of BGT-based methods at low effective pressure, a new rock physics model applicable at low effective pressure is desirable and would be an improvement.

This report uses the measured S-wave velocities for recovered core samples by Lee and others (2008) at the KC151 site, reconstituted sands by Zimmer (2003), and well-log data at the Walker Ridge and Alaminos Canyon sites acquired during JIP Leg II (Boswell and others, 2009). For velocities, BGT with dry moduli of the sediments proposed by Pride (2005) and Lee (2005) is used. In order to model the effect of effective pressure on velocity, a pressure-dependent consolidation parameter is incorporated into BGT.

\section{Descriptions of Data}

S-wave velocities $(V)$ of reconstituted sediment at the $\mathrm{KC} 151$ site measured in the frequency range of $5-70 \mathrm{kHz}$ (Lee and others, 2008) and reconstituted GOM and Galveston sands measured by Zimmer (2003) with a frequency of $150 \mathrm{kHz}$ along with well log velocities were analyzed to study the effect of the effective pressure on $V_{s}$. Effective pressure used by Lee and others (2008) ranged from 0 to $2.31 \mathrm{MPa}$ with a single loading and unloading cycle and 0.1 to $20 \mathrm{MPa}$ with many loading and unloading cycles for measurements by Zimmer (2003).

The S-wave velocities at the Walker Ridge site (WR313-H well located at the water depth of $6,450 \mathrm{ft}$ $[1,953 \mathrm{~m}]$ ) and at the Alaminos Canyon site (AC21-A well, located at the water depth of 4,889 ft or $[1,490 \mathrm{~m}]$ ) were acquired using MP3 (Schlumberger's newer generation acoustic tool). The tool, located $35.45 \mathrm{ft}(10.8 \mathrm{~m})$ from the drill bit, was the closest tool in the LWD logging assembly. Because of the short distance from the drill bit, adverse effects of the borehole such as washouts were minimized. The P-wave velocities $\left(V_{p}\right)$ were estimated from the waveform in the frequency range of $2.5-4.5 \mathrm{kHz}$ and S-wave velocities were processed using frequencies less than $3 \mathrm{kHz}$. Although high-quality P-wave velocities were acquired throughout the logged interval (Guerin and others, 2009), the S-wave velocities were interpretable only for limited depth ranges due to the low signal-to-noise ratio of the shear arrivals. In spite of this limitation of the S-wave velocity, the LWD S-wave data provide a critical dataset to test rock physics models at low effective pressure, as presented in this report.

Sediments obtained at the KC151 site, at $4,369 \mathrm{ft}$ $(1,323 \mathrm{~m})$ water depth in the northern GOM (fig. 1) are classified as inorganic clays with high plasticity (Yun and others, 2006). Sediments at the KC151 site are similar to those measured by MP3 during JIP Leg II. 


\section{Theory}

\section{Biot-Gassmann Theory with Consolidation Parameter}

$V_{p}$ and $V_{s}$ of fluid (water)-saturated sediments can be written as:

$$
V_{p}=\sqrt{\frac{k+4 \mu / 3}{\rho_{b}}} \text { and } V_{s}=\sqrt{\frac{\mu}{\rho_{b}}}
$$

where $k$ and $\mu$ are bulk and shear moduli of the sediment, $\rho_{b}$ is the bulk density of sediment given by $\rho_{b}=\rho_{s}(1-\varphi)+\rho_{w} \varphi$, and subscripts $s$ and $w$ refer to sediment grain and fluid, respectively.

According to BGT, the bulk modulus of the sediments is given by

$$
k=K_{s}\left(1-\beta_{p}\right)+\beta_{p}^{2} K_{a v}
$$

with

$$
\frac{1}{K_{a v}}=\frac{\left(\beta_{p}-\varphi\right)}{K_{s}}+\frac{\varphi}{K_{w}},
$$

and the shear modulus given by (Lee, 2005) is

$$
\mu=\mu_{s}\left(1-\beta_{s}\right)
$$

where $\beta_{p}$ and $\beta_{s}$ are appropriate Biot coefficients for bulk and shear moduli.

The Biot coefficient shown in equations 2 and 3 can be written as (Lee, 2005):

$$
\begin{gathered}
\beta_{p}=\frac{\varphi(1+\alpha)}{(1+\alpha \varphi)} \text { and } \beta_{s}=\frac{\varphi(1+\gamma \alpha)}{(1+\gamma \alpha \varphi)}, \\
\text { with } \gamma=\frac{1+2 \alpha}{1+\alpha}
\end{gathered}
$$

where $\alpha$ is the consolidation parameter (Pride, 2005; Lee, 2005). Pride (2005) used a constant value for $\gamma$, whereas Lee (2005) used $\gamma$ as a function of the consolidation parameter. Lee (2005) showed that using $\gamma$ as a function of $\alpha$ yields more accurate velocities, particularly for unconsolidated sediments.

\section{Parameters $\alpha$ and $\gamma$}

The consolidation parameter $\alpha$ depends on the effective pressure and degree of consolidation and should be a function of depth or effective pressure. Depth (or effective pressure) dependent $\alpha$ is proposed by the following equation:

$$
\alpha_{i}=\alpha_{o}\left(p_{o} / p_{i}\right)^{n} \approx \alpha_{o}\left(d_{o} / d_{i}\right)^{n}
$$

where $\alpha_{o}$ is the consolidation parameter at the effective pressure $p_{o}$ or depth $d_{o}, \alpha_{i}$ is the consolidation parameter at the effective pressure $p_{i}$ or depth $d_{i}$, and $n$ is an appropriate constant.
As mentioned previously, Pride (2005) used a constant $\gamma$ irrespective of the consolidation parameter $\alpha$. Lee (2005) used $\gamma$ as a function of $\alpha$ (equation 4) in such a way that $\gamma$ increases as $\alpha$ increases. Equation 5 indicates that the logarithm of $\alpha$ with respect to the effective pressure is a linear function of pressure. The slope of the linear function controls how rapidly the velocity changes with respect to effective pressure.

Figure 2 shows measured velocities of GOM sands (Zimmer, 2003), and figure 3 shows various calculated $\alpha$ 's. Figure $3 A$ shows the calculated $\alpha$, assuming $\gamma=(1+2 \alpha) /(1+\alpha)$ from the P-wave velocity and porosity data for GOM reconstituted sands using the method proposed by Lee (2006c). As shown in figure $3 A, \gamma$ is virtually constant irrespective of $\alpha$ whereas $\alpha$ increases as the effective pressure decreases. However, the increase of logarithmic $\alpha$ is not a linear function of the logarithmic effective pressure as assumed in equation 5 . In other words, the exponent $n$ shown in equation 5 is not a constant, but rather a function of effective pressure.

To a first-order approximation, there are two linear functions of $\alpha$ as a function of effective pressure, with the transition occurring at approximately 4 to $5 \mathrm{MPa}$ (fig. $3 A$ ).

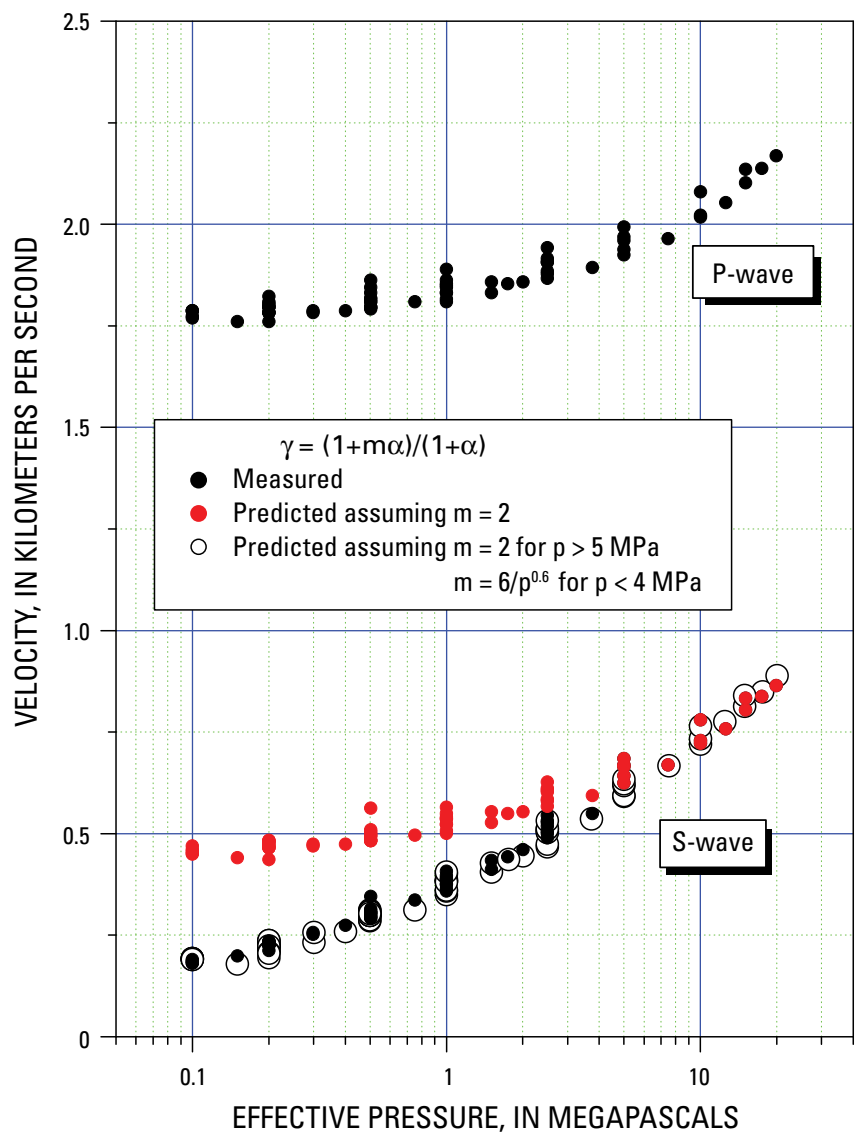

Figure 2. Measured velocities for the Gulf of Mexico (GOM) sands by Zimmer (2003) with various predicted S-wave velocities. 

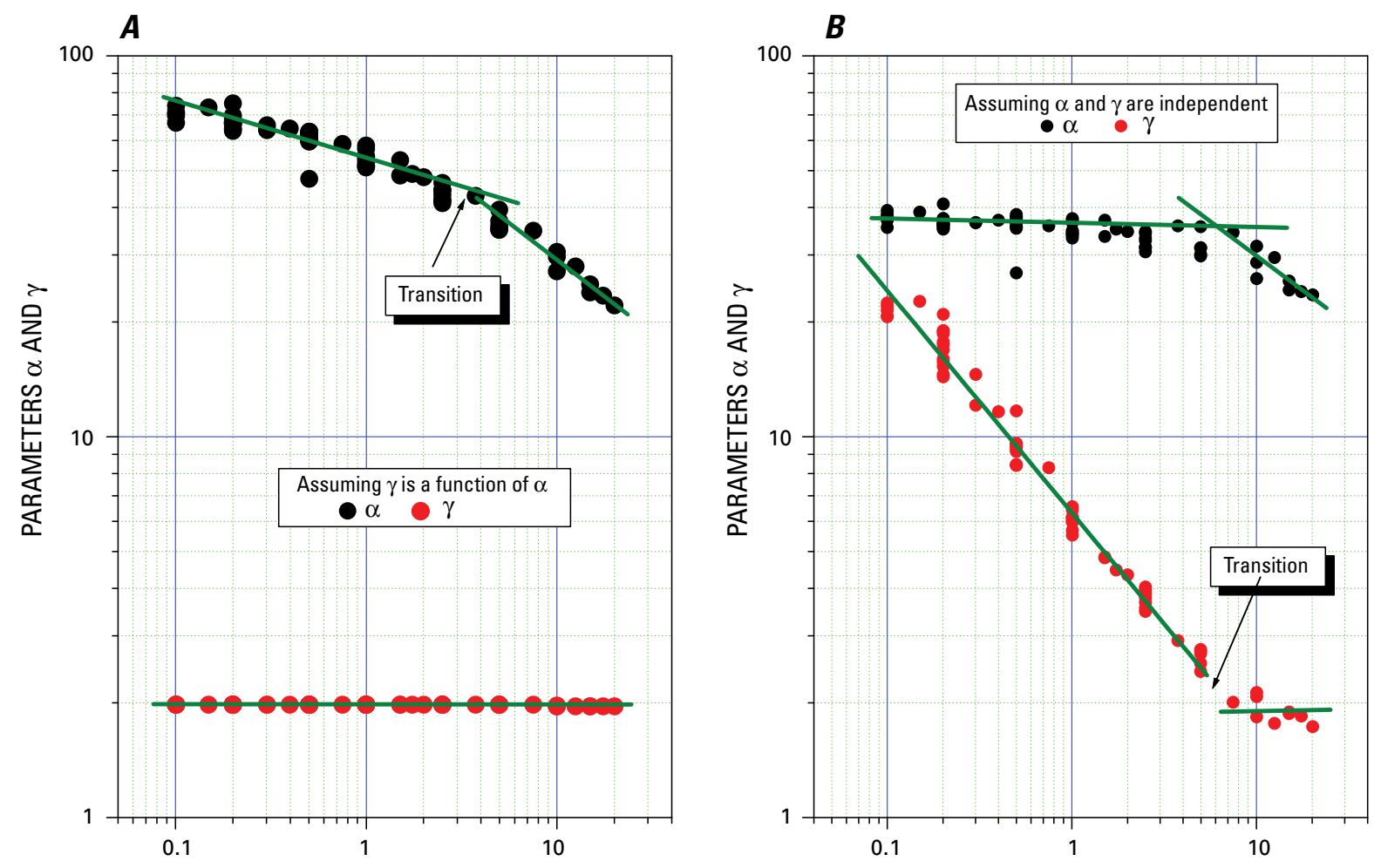

EFFECTIVE PRESSURE, IN MEGAPASCALS

Figure 3. Estimated parameters from velocities and porosities of Gulf of Mexico sands measured by Zimmer (2003). $A$, consolidation parameter $\alpha$ from the P-wave velocity and porosity assuming $\gamma=(1+2 \alpha) /(1+\alpha)$. $B$, parameters $\alpha$ and $\gamma$ calculated from the P-wave, $\mathbf{S}$-wave velocities, and porosity assuming $\alpha$ and $\gamma$ are independent variables.

For effective pressure less than $5 \mathrm{MPa}$, the linear function is given by $\alpha=1.72 p^{-0.15}$ and for $p>5 \mathrm{MPa}$, it is given by $\alpha=1.81 p^{-0.35}$. The calculated S-wave velocities using parameters shown in figure $3 A$ are shown in figure 2 as red circles. The calculated S-wave velocities are accurate for $p>5 \mathrm{MPa}$, whereas the calculated S-velocities are much higher than those measured for $p<4 \mathrm{MPa}$. This implies that equation 4 is accurate to model velocities of sediments for an effective pressure greater than about 4-5 MPa, but overestimates S-wave velocity when $p<4 \mathrm{MPa}$.

Figure $3 B$ shows calculated $\alpha$ and $\gamma$ assuming these parameters are independent of each other. These parameters are calculated by fitting both P- and S-wave velocities by adjusting $\alpha$ and $\gamma$ independently. Figure $3 B$ indicates, when $p>5 \mathrm{MPa}$, that $\alpha$ and $\gamma$, as calculated under the assumption that these parameters are independent, are similar to those calculated assuming $\gamma=(1+2 \alpha) /(1+\alpha)$. In other words, equation 4 is accurate for $p>4-5 \mathrm{MPa}$. However, the calculated $\alpha$ and $\gamma$ in figure $3 B$ differ from those shown in figure $3 A$ for $p<4 \mathrm{MPa}$. To accurately model both $\mathrm{P}$ - and $\mathrm{S}$-wave velocities for $p<4-5 \mathrm{MPa}$, equation 4 is not adequate and new parameters are required.

To model velocities at low effective pressure, the following equations are proposed:

$$
\begin{gathered}
\gamma=(1+m \alpha) /(1+\alpha) \text { with } m=6 p^{-0.6} \text { for } p<4 \mathrm{MPa} \text { and } \\
m=2 \text { for } \mathrm{p}>5 \mathrm{Mpa},
\end{gathered}
$$

and a linear interpolation between 2 and $m$ for $4<p<5 \mathrm{MPa}$. The large open circles in figure 2 show the calculated S-wave velocities using equation 6 . The calculated S-wave velocities are accurate for all ranges of effective pressure. It is noted that the parameter transition near $p \approx 4-5 \mathrm{MPa}$ shown in figure 3 is based on velocities for clean sands. Transition pressure for shale or shaly sand, therefore, may be different from that shown in figure 3 , and it could be updated when such data are available.

Equation 6 is valid only for fluid-saturated sediment. In the case that the pore space is filled with air (dry rock) or sediment is partially gas saturated, $\gamma=1$ should be used irrespective of the effective pressure (Lee, 2005). 


\section{Measured S-wave Velocity}

Figure 4 shows the relation between P-and S-wave velocities from various sources. Data by Han and others (1986) are for consolidated sediments and other data are for unconsolidated sediments. There are two distinct trends: one is for S-wave velocity greater than about $1 \mathrm{~km} / \mathrm{s}$ $\left(V_{p}=2.286 V_{s}^{0.672}\right)$ and the other is for velocity less than about $0.6 \mathrm{~km} / \mathrm{s}\left(V_{p}=2.042 V_{s}^{0.103}\right)$. Modeling results using pressuredependent consolidation parameter $\alpha=3(5 / p)^{0.6}$ with a constant $m=2$ for consolidated sediment having $\varphi=0.15$ (red solid line), and for unconsolidated sediment (red dashed line) having $\varphi=0.38$ with $\alpha=40(5 / p)^{0.6}$ are shown for comparison. Although the modeled relation for unconsolidated sediments mimics the measured relation for S-wave velocity up to 1 $\mathrm{km} / \mathrm{s}$, it deviates significantly from the measured relation for $\mathrm{S}$-wave velocities less than about $0.6 \mathrm{~km} / \mathrm{s}$. Figure 4 indicates that two different velocity trends exist and suggests that two different approaches would be required to predict S-wave velocity, similar to that suggested in figure 2 .

\section{Predicting S-wave Velocity at Low Effective Pressure}

One important factor to be considered for the elastic inversion of unconsolidated shallow sediment is the S-wave velocity at low effective pressure (Lee, 2006a). It is desirable to accurately predict the S-wave velocity less than about $0.6 \mathrm{~km} / \mathrm{s}$ or at low effective pressure from the P-wave velocity to effectively implement the seismic inversion. S-wave velocities less than $0.6 \mathrm{~km} / \mathrm{s}$ are common. Kumar and others (2006) reported that S-wave velocities estimated from multicomponent ocean-bottom seismograph data at the Hydrate Ridge, offshore Oregon, are in the range of 0.15 to $0.35 \mathrm{~km} / \mathrm{s}$. Also, $\mathrm{S}$-wave velocities analyzed from the multicomponent oceanbottom cable data in the GOM by Hardage and others (2006) are in the range of $0.3 \mathrm{~km} / \mathrm{s}$. The well log S-wave velocities at Hydrate Ridge that were acquired during Ocean Drilling Program Leg 204 vary from $0.25 \mathrm{~km} / \mathrm{s}$ to $0.65 \mathrm{~km} / \mathrm{s}$ (Lee and Collett, 2006).

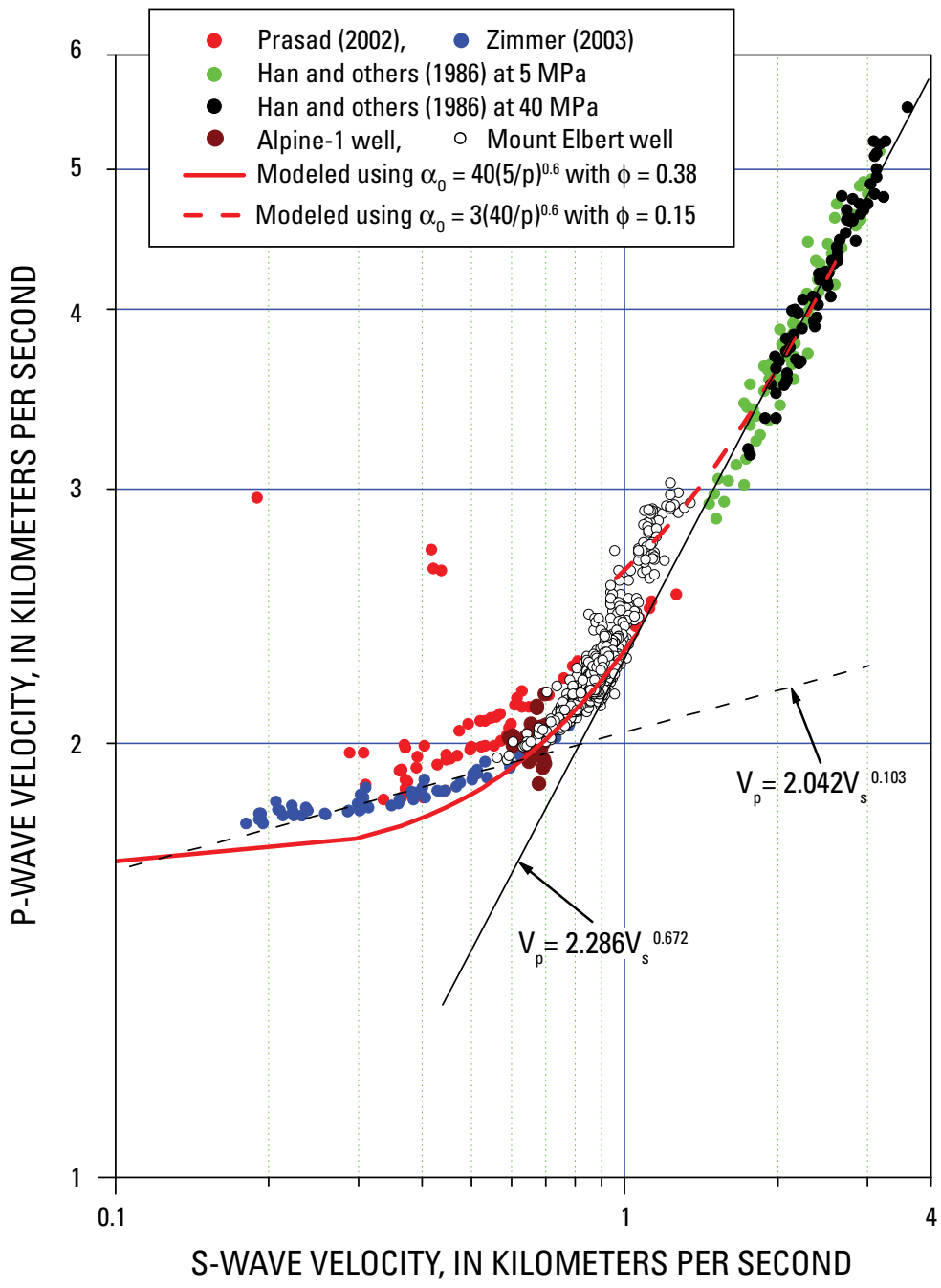

Figure 4. Relation between P-wave and S-wave velocities from various sources; laboratory data from Han and others (1986), Prasad (2002), and Zimmer (2003), and well log data from the Mount Elbert and Alpine-1 wells, North Slope of Alaska. 
The use of equations 1 and 4 provides a means of predicting S-wave velocities based on $\mathrm{P}$-wave velocities and porosities of sediments because the parameter $\alpha$ relates both bulk and shear moduli of a dry frame. Defining the predicted P-wave velocity using the BGT, with the moduli derived from equations 1 and $4 V_{p}^{*}$ as and as $V_{p}^{m}$ for measured $P$-wave velocity, the consolidation parameter can be calculated by solving the following equation (Lee, 2006c):

$$
V_{p}^{*}(\alpha)-V_{p}^{m}=0 .
$$

Therefore, the shear modulus can be calculated using equation 3 with equation 4 by substituting the consolidation parameter estimated from equation 7 into equation 4.

If $m$ shown in equation 6 is used to solve equation 7, it is the proposed method of predicting S-wave velocity in this report. If $m=2$ for all effective pressure shown in equation 6 is used to solve equation 7 , it is the conventional method and identical to that shown in Lee (2006c).

\section{Wet Sands Measured at High Frequency}

Using $m=2$ in equation 6 (conventional method) resulted in overestimating S-wave velocities that are predicted on the basis of the P-wave velocities measured at the high frequency of $150 \mathrm{kHz}$ for GOM sands by Zimmer (2003), as shown in figure 2. Currently available rock physics models (for example, Walton, 1987; Greenberg and Castagna, 1992; Xu and White, 1996; Lee, 2006b) consistently predict a slightly higher S-wave velocity from the porosity and P-wave velocity for GOM sands. Figure $5 A$ shows predicted S-wave velocities for GOM and Galveston sands (Zimmer, 2003) with $m=2$ irrespective of the effective pressure (conventional method), whereas figure $5 B$ shows the predicted S-wave velocities using $m=6 p^{-0.6}$ for effective pressures less than $4 \mathrm{MPa}$ and $m=2$ for pressures greater than $5 \mathrm{MPa}$ (proposed method). Figure $5 \mathrm{~A}$ indicates that using $m=2$ results in accurate prediction of S-wave velocities for effective pressures greater than about $5 \mathrm{MPa}$, which corresponds to an S-wave velocity of about $0.6 \mathrm{~km} / \mathrm{s}$ but overestimates S-wave velocities for effective pressures less than about $5 \mathrm{MPa}$. The overestimation increases as the effective pressure decreases.

Predicted S-wave velocities for GOM sands using the proposed method are more accurate than those for the Galveston sands because the parameter $m$ was derived specifically from the GOM sands. However, the use of $m$ as a function of effective pressure shown in equation 6 also worked fairly well for the Galveston sands.

The S-wave prediction methods suggested by Greenberg and Castagna (1992), Xu and White (1996), and Lee (2006b, 2006c) are based on the Gassmann type equation, which is valid at low frequency and ignores the velocity dispersion. Thus, one interpretation for the cause of the overestimation of S-wave velocity for GOM sands at low effective pressure is that $\mathrm{P}$-wave velocity dispersion was not accounted for. An alternative interpretation is that the conventional method based on the BGT is not accurate at low effective pressure.

\section{Dry Sands Measured at High Frequency}

If overestimation of S-wave velocities for wet GOM or Galveston sands is caused by velocity dispersion due to fluid in the pore space, the prediction of S-wave velocities for dry rock (air filled in the pore spaces) should be accurate using the same rock physics model shown in this report. Figures $6 A$ and $6 B$ show the measured and predicted S-wave velocities for dry samples of GOM and Galveston sands measured by Zimmer (2003) using $\gamma=1$ irrespective of the effective pressure. As opposed to the results shown in figure 5, the predicted S-wave velocities are accurate both for the GOM and Galveston sands. The results shown in figure 6 indicate that the pore fluid is probably the primary cause for the overestimation of S-wave velocities shown in figure $5 \mathrm{~A}$.

\section{Wet Shale Measured at Low Frequency}

The MP3 P-wave data were processed with a $4.5-\mathrm{kHz}$ low-pass filter, and the S-wave data were processed with a 3.0-kHz low-pass filter. Figure $7 A$ shows the measured MP3 shear-wave velocities with two predicted $S$-wave velocities from the measured P-wave velocity and porosity at WR313-H well, GOM. S-wave velocities using a constant $m=2$ (conventional method) are higher than those predicted using $m=6 p^{-0.6}$ (proposed method) and agree better with the measured MP3 shear-wave velocity data. The effective pressure was estimated assuming a normal pressure regime in this area. For example, the effective pressure at $500 \mathrm{ft}$ below sea floor (fbsf) is about $1.5 \mathrm{MPa}$.

The S-wave velocities by Lee and others (2008) were measured from reconstituted samples collected at the KC151 site, between the WR and AC sites (fig. 1) and lithologies at both sites are shale. The MP3 data at different wells acquired during JIP Leg II show a similar P-wave velocity trend with depth, particularly at depths less than about $500 \mathrm{fbsf}$. Therefore, it is assumed that the P-wave velocities at the KC151-2 well are similar to those measured P-waves at the Walker Ridge and Alaminos Canyon areas. The measured S-wave velocities by Lee and others (2008) were also plotted in figure $7 A$ for WR313-H as stars. Although the locations of the two sites are not the same, the S-wave velocities with depth (effective pressure) at the $\mathrm{KC} 151$ site agree better with the predicted S-wave velocities using $m=2$ rather than $m$ as a function of the effective pressure. Figure $7 B$ shows predicted and measured S-wave velocities at the AC21-A well and supports the previous observation at the WR313-H well.

In summary, the conventional method accurately predicts $\mathrm{S}$-wave velocities at all ranges of effective pressure from the $\mathrm{P}$-wave velocities measured at low frequencies less than 70 $\mathrm{kHz}$, whereas it overestimates $\mathrm{S}$-wave velocities from $\mathrm{P}$-wave velocities measured at low effective pressure less than $4 \mathrm{MPa}$ 

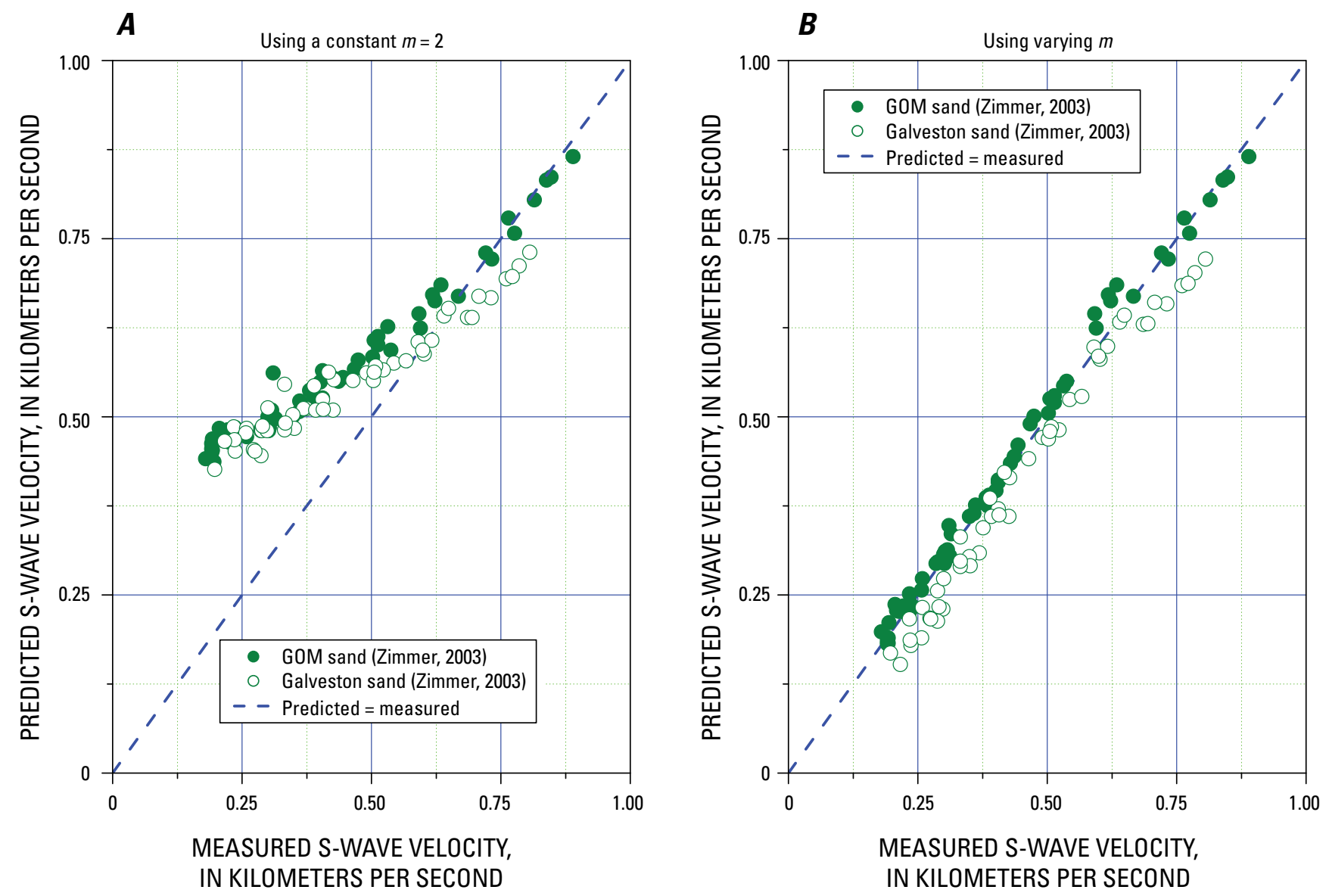

Figure 5. Measured and predicted S-wave velocities for Gulf of Mexico (GOM) and Galveston sands by Zimmer (2003). $A$, using the conventional method (equation 4). $B$, using the proposed method (equation 6).

at frequencies greater than $150 \mathrm{kHz}$. On the other hand, the proposed method accurately predicts S-wave velocities at all ranges of effective pressure from the P-wave velocities measured at high frequencies, but it underestimates S-wave velocities from P-wave velocities measured at low frequencies such as well log velocities.

\section{Assessment of Prediction Methods}

\section{Comparison with Walton's Theory}

To test whether the overestimation of S-wave velocities for wet GOM sands is caused by the inaccuracy of the rock physics model used here (equations 1-5), the theory by Walton (1987), which is well established for the determination of velocities of unconsolidated sediments, is investigated. For unconsolidated sands and soils, bulk and shear moduli of the frame are well modeled using the following variant of Walton's theory (see Pride [2005] for details):

$$
\begin{gathered}
k_{d}=\frac{1}{6}\left[\frac{4(1-\varphi)^{2} q^{2} p_{o}}{\pi^{4} C_{s}^{2}}\right]^{1 / 3} \frac{\sqrt{p_{i} / p_{o}}}{\left\{1+\left[16 p_{i} /\left(9 p_{o}\right)\right]^{4}\right\}^{1 / 24}} \\
\mu=\mu_{d}=\frac{3 k_{d}}{5}
\end{gathered}
$$

where $q$ is the coordination number (average number of grain contacts per grain) and increases as effective pressure increases (reference effective pressure $p_{o}$ is commonly on the order of $10 \mathrm{MPa}$ ) and $C_{s}$ is a compliance parameter given by

$$
C_{s}=\frac{1}{4 \pi}\left(\frac{1}{\mu_{s}}+\frac{1}{K_{s}+\mu_{s} / 3}\right) .
$$

A sediment with unimodal grain-size distributions and random grain packs, which is similar to reconstituted GOM sands by Zimmer (2003), typically has $0.32<\varphi<0.36$ and $8<q<11$.

Figure 8 shows the calculated $\mathrm{P}$ - and $\mathrm{S}$-wave velocities using Walton's (1987) equation with $\varphi=0.4, q=9$, and $p_{o}$ $=18 \mathrm{MPa}$ as solid red lines. The predicted S-wave velocities from Walton's equation agree well with measured S-wave velocities, and S-wave velocities are proportional to about 

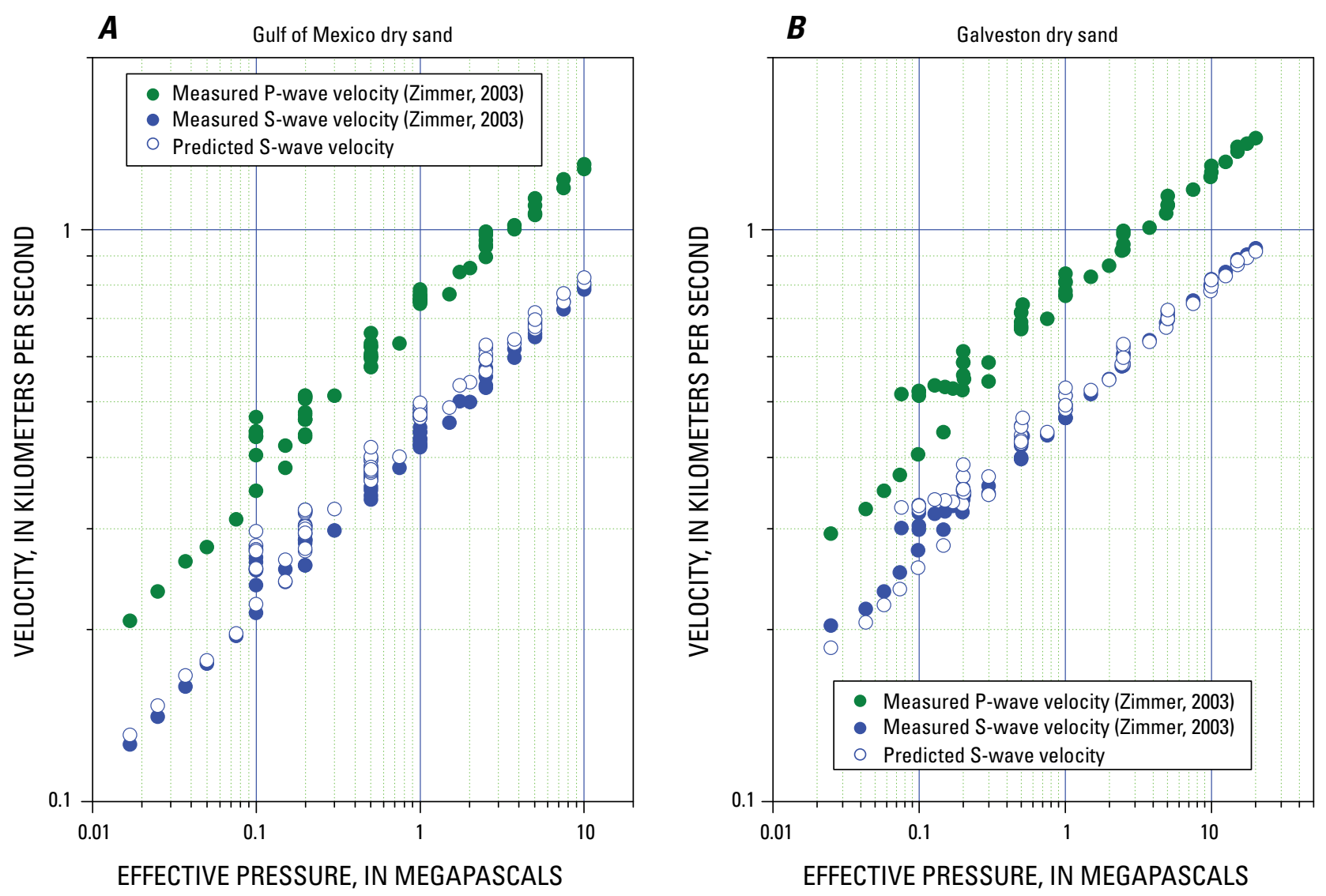

Figure 6. Measured and predicted S-wave velocities for dry sands by Zimmer (2003). A, Gulf of Mexico (GOM) sands. $B$, Galveston sands.

$1 / 4$ power of effective pressure. Also shown in figure 8 as blue dashed lines are the modeled velocities using the BGT with $\alpha=45(5 / p)^{0.6}$ with $\varphi=0.4$ and $m=2$. The results using the BGT are almost identical to those of the Walton (1987) for effective pressure less than $5 \mathrm{MPa}$ but are more accurate for effective pressures greater than $5 \mathrm{MPa}$. By using a pressure-dependent coordination number or other adjustment of parameters for Walton's equation, the performance of the Walton model could be improved. However, figure 8 indicates that the result using BGT with $m=2$ is as good as the result by Walton's equation.

The predicted $\mathrm{P}$-wave velocities using the Walton equation and BGT with consolidation parameter with equation 4 behave similarly. For effective pressure less than about 3 $\mathrm{MPa}$, both equations predict similar P-wave velocities that are slightly less than the measured velocities. On the other hand, for effective pressure greater than about $3 \mathrm{MPa}$, BGT predicts accurate $\mathrm{P}$-wave velocities, whereas the Walton equation underestimates the P-wave velocity. The key observation of figure 8 is that both BGT and Walton's theory underestimate the P-wave velocities for GOM wet sands for a given S-wave velocity, and the underestimation increases as the effective pressure decreases, which is similar to the behavior of the overestimation of S-wave velocity shown in figure 2 . In other words, the underestimation of the P-wave velocity or overestimation of S-wave velocity is not likely caused by the inaccuracy of the rock physics model shown in equations $1-5$.

\section{Parameter $\boldsymbol{m}$}

The parameter $m$, shown in equation 6 , determines whether or not the conventional BGT-based rock physics models are accurate at low effective pressure. If using $m$ as a function of the effective pressure is more accurate than using $m=2$ irrespective of the effective pressure, the conventional method is inaccurate. Figure $9 A$ shows the predicted $\mathrm{P}$-wave velocities using $m=2$ irrespective of the effective pressure for GOM sands by Zimmer (2003). If a pressure dependent $m$-for example, $m=6 / p^{0.6}$-is used, the predicted P-wave velocities would be almost identical to the measured $\mathrm{P}$-wave velocities indicated as solid dark green dots in figure $9 \mathrm{~A}$. Figure $9 B$ shows the difference between predicted $\mathrm{P}$-wave velocities with $m=2$ and measured P-wave velocities for GOM and Galveston sands. The difference increases as the 

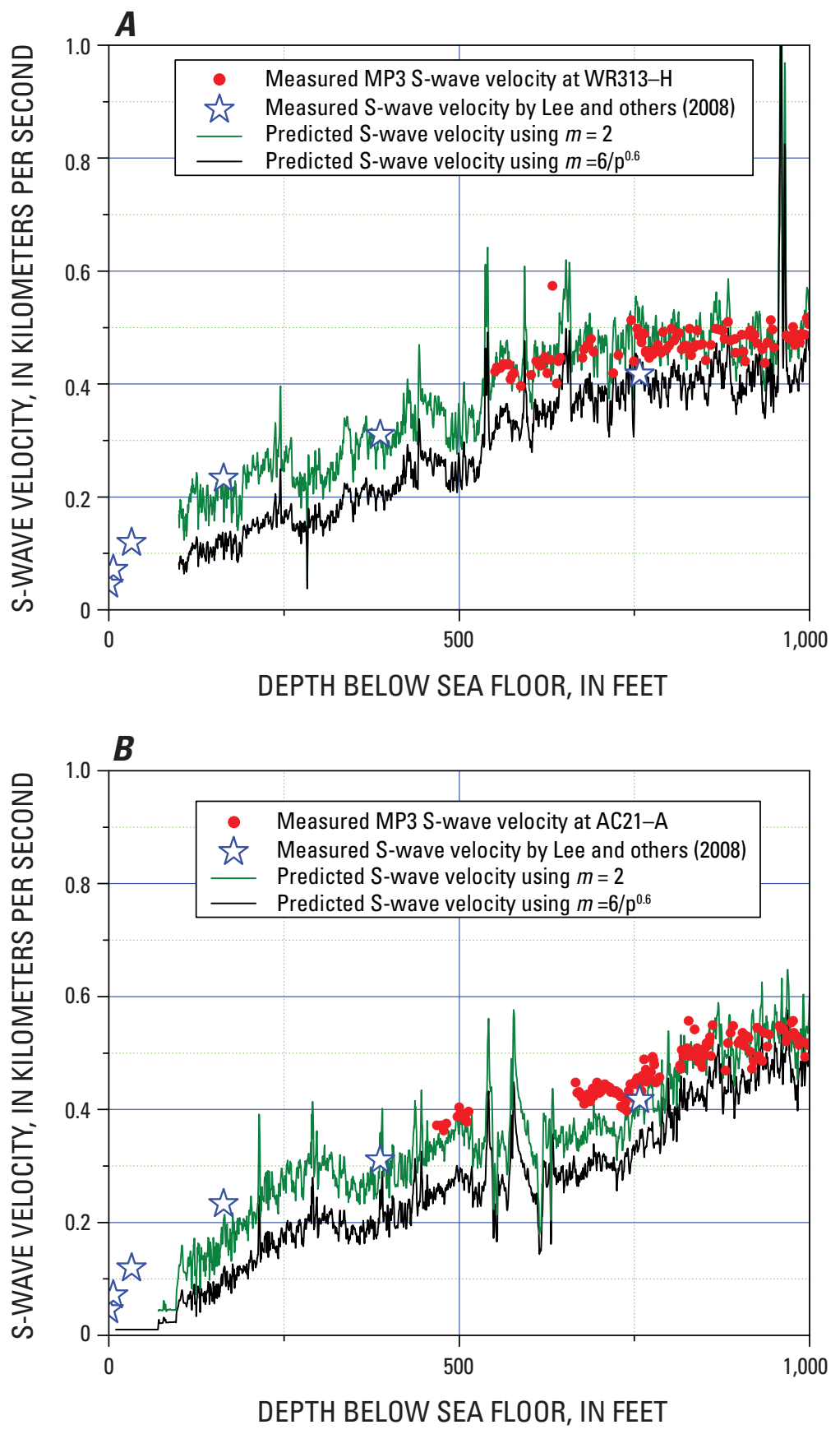

Figure 7. Well-log measured and predicted S-wave velocities at the Gulf of Mexico with S-wave velocities measured by Lee and others (2008). A, WR313-H well. B, AC21-A well. 


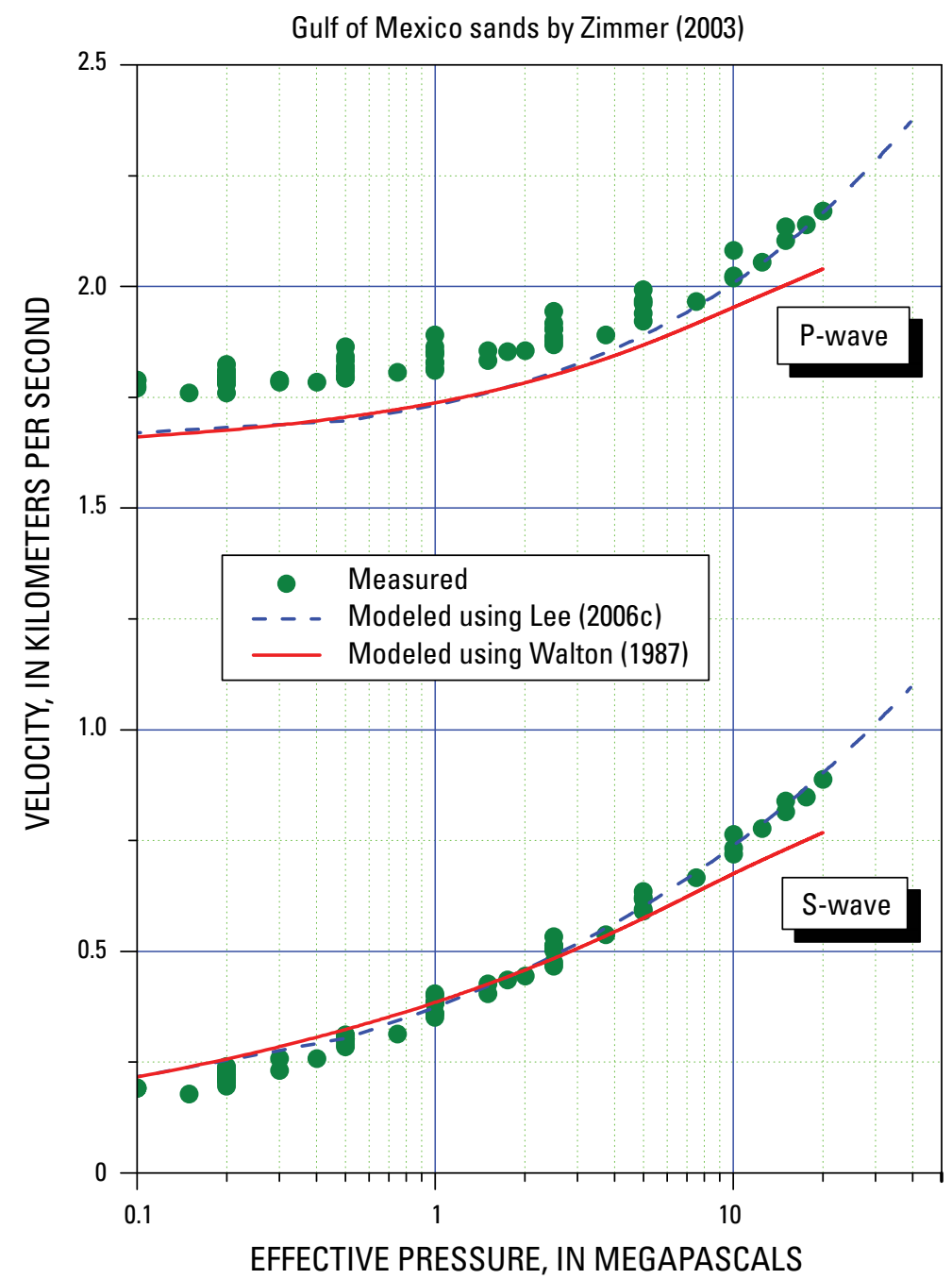

Figure 8. Measured velocities of Gulf of Mexico (GOM) sands and predicted velocities using the Walton's equation and the BiotGassmann theory with the consolidation parameter with $m=2$ shown in this report.

effective pressure decreases, similar to the behavior of the P-wave velocity dispersion (Zimmer, 2003).

This result implies that the velocity dispersion can be accounted for by using $m=6 / p^{0.6}$, at least for the GOM sands. If the overestimation of the $\mathrm{S}$-wave is caused by the inaccuracy of the BGT-based method, $m=6 / p^{0.6}$ provides more accurate $\mathrm{S}$-wave velocities at low effective pressure irrespective of the frequency. However, the results shown for the well $\log$ velocities and those measured by Lee and others (2008) indicate that $m=2$, the conventional method, is more accurate. Therefore, the overestimation of S-wave velocities for GOM sands is likely due to $\mathrm{P}$-wave velocity dispersion rather than the inaccuracy of the conventional method.

\section{Velocity Dispersion}

Velocity dispersion is primarily caused by the interaction between the pore fluid and the porous solid. Velocities increase as frequency increases because the viscosity of the fluid resists shearing of the rock volume and is more pronounced at high frequency. As shown in the previous example for the GOM sands, BGT predicts accurate S-wave velocities for high effective pressure, whereas it overestimates $S$-wave velocities at low effective pressure. This discrepancy is mainly caused by the P-wave velocity dispersion.

The effect of pore fluid is more pronounced on the P-wave velocities at low effective pressure (Zimmer, 2003). 

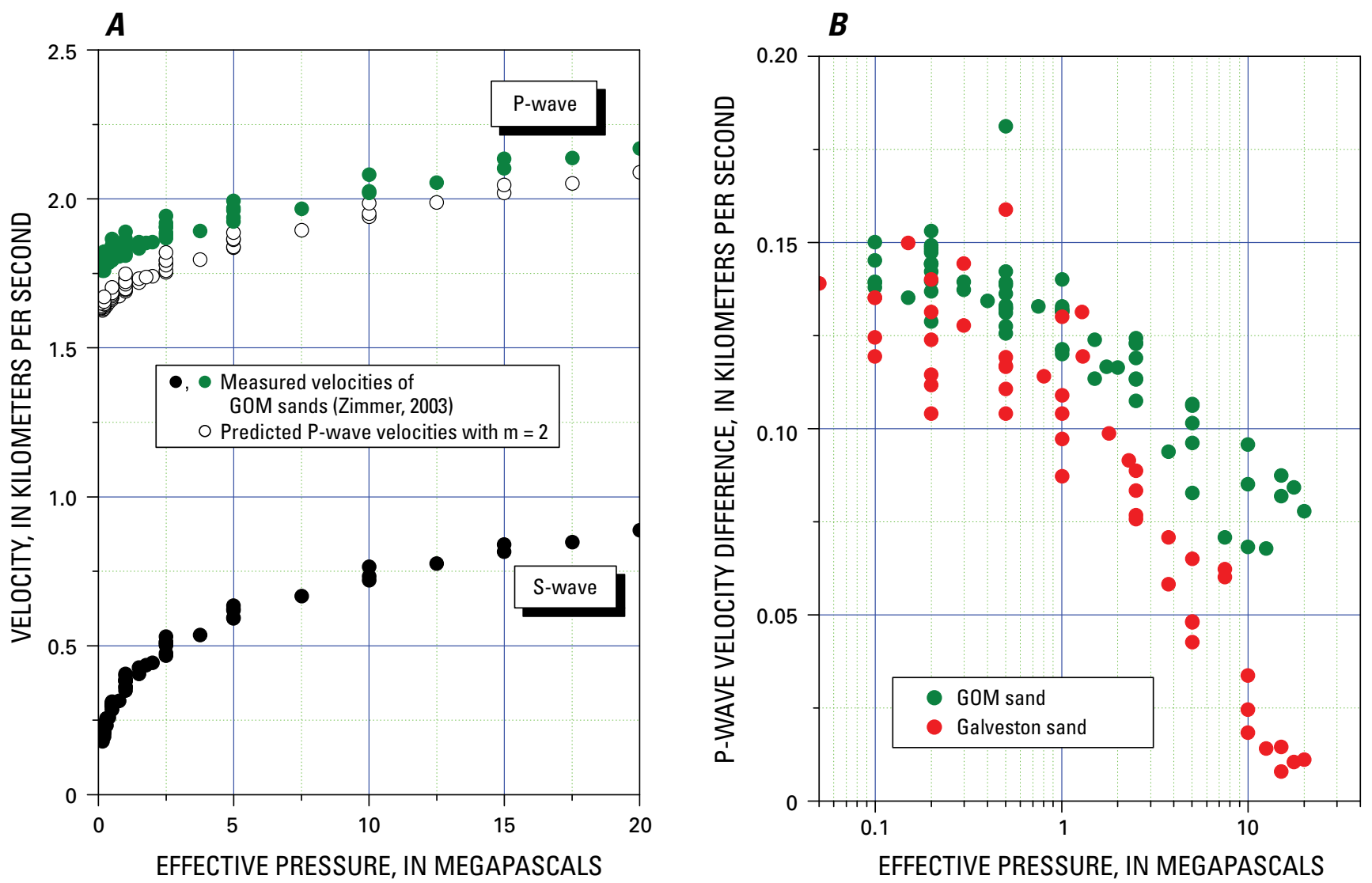

Figure 9. Difference between measured and predicted velocities of Gulf of Mexico (GOM) sands by Zimmer (2003). $A$, predicted $\mathrm{P}$-wave velocities from $\mathrm{S}$-wave velocities for GOM sands using $m=2$. $B$, difference between the predicted P-wave velocity with $m=2$ and the measured velocities for GOM and Galveston sands.

S-wave velocities predicted using Gassmann theory for a variety of samples are close to the measured velocities, whereas the predicted P-wave velocities are always smaller than the measured velocities (Zimmer, 2003). On the basis of this observation, Zimmer concluded that the dispersion mechanism significantly affects only the bulk modulus of the sediments, not the shear modulus. Consequently, the Gassmann type equation (such as equations used in this report) predicts higher $\mathrm{S}$-wave velocity calculated from the $\mathrm{P}$-wave velocity that was measured at low effective pressure with higher frequencies.

As shown previously, the predicted S-wave velocities from the P-wave velocities are accurate for dry sands (fig. 6) and well-log velocities at low frequencies (fig. 7). Taking these results with the velocity dispersion, the overestimation of S-wave velocity at low effective pressure from the P-wave velocity measured at high frequencies in the range of $150 \mathrm{kHz}$ is primarily caused by velocity dispersion.

\section{Conclusions}

Measured data indicate that there are two distinct relations between the $\mathrm{P}$-wave velocity and the $\mathrm{S}$-wave velocity. One trend is for the S-wave velocity that is less than about $0.6 \mathrm{~km} / \mathrm{s}$, which corresponds approximately to an effective pressure less than 4-5 MPa. The other relation is valid for the $\mathrm{S}$-wave velocity that is greater than about $0.6 \mathrm{~km} / \mathrm{s}$. However, the same rock physics model with $m=2$ (conventional method) can be applied to relate the P-wave velocity to the $\mathrm{S}$-wave velocity, if the $\mathrm{P}$-wave velocity is measured at low frequencies.

Conventional rock physics models, which are based on the classical Biot-Gassmann theory, predicted higher S-wave velocities from the P-wave velocities, which were measured at high frequencies and at low effective pressures less than about 4-5 MPa, and the overestimation increases as the effective 
pressure decreases. The primary reason for the overestimation of the S-wave velocity is likely due to the P-wave velocity dispersion.

The logging-while-drilling velocity logs acquired in the Gulf of Mexico indicate that Biot-Gassmann type equations, which are the low-frequency approximation of the Biot equation, appear to be appropriate for predicting S-wave velocities for well logs or seismic data. However, because the S-wave velocities at low effective pressure investigated in this report were limited to shale, more accurate velocity data for sands measured both at low effective pressure and low frequency are desirable to further refine the S-wave prediction method.

\section{Acknowledgments}

I would like to thank Timothy Collett (U.S. Geological Survey) for providing the MP3 well-log data for this study and for his continuous support and encouragement throughout the investigation. I also thank Warren Agena and Lauri Burke (U.S. Geological Survey) for their many suggestions and comments.

\section{References Cited}

Boswell, Ray, Collett, T.S., Frye, M., McConnell, D., Shedd, W., Dufrene, R., Godfriaus, P, Mrozewski, S., Guerin, G., and Cook, A., 2009, Gulf of Mexico Gas Hydrate Joint Industry Project Leg II-Technical Summary: Proceedings of the Drilling and Scientific Results of the 2009 Gulf of Mexico Gas Hydrate Joint Industry Project Leg II, 28 p.

Dvorkin, Jack, Prasad, M., Sakai, A., and Lavoie, D., 1999, Elasticity of marine sediments: Geophysical Research Letters, v. 26, p. 1781-1784.

Greenberg, M.L., and Castagna, J.P., 1992, Shear-wave velocity estimation in porous rocks-Theoretical formulation, preliminary verification and applications: Geophysical Prospecting, v. 40, p. 195-209.

Guerin, Gilles, Cook, A., Mrozewski, S., Collett, T., and Boswell, R., 2009, Gulf of Mexico Gas Hydrate Joint Industry Project Leg II-Green Canyon 955 LWD operations and results: Proceedings of the Drilling and Scientific Results of the 2009 Gulf of Mexico Gas Hydrate Joint Industry Project Leg II, $29 \mathrm{p}$.

Han, D.H., Nur, A., and Morgan, D., 1986, Effects of porosity and clay content on wave velocities in sandstone: Geophysics, v. 51, p. 2093-2107.

Hardage, B.A., Muray, P., Sava, D., Backus., M.M., and Graebner, R., 2006, Evaluation of deepwater gas hydrate systems: The Leading Edge, v. 25, p. 572-576.
Hutchinson, D.R., Boswell, R., Collett, T.S., Dai, J., Dugan, B., Frye, M., Jones, E., McConnell, D., Rose, K., Ruppel, C., Shedd, W., Shelander, D., and Wood, W., 2009, Gulf of Mexico Gas Hydrate Joint Industry Project Leg II-Walker Ridge 313 Site Selection: Proceedings of the Drilling and Scientific Results of the 2009 Gulf of Mexico Gas Hydrate Joint Industry Project Leg II, 35 p.

Jørstad, Arild, Mukerji, T., and Mavko, G., 1999, Model-based shear-wave velocity estimation versus empirical regressions: Geophysical Prospecting, v. 47, p. 785-797.

Kumar Dhananjay, Sen, M.K., and Bang, N.L., 2006, Seismic characteristics of gas hydrates at Hydrate Ridge, offshore Oregon: The Leading Edge, v. 25, p. 610-612, 614.

Lee, J.Y., Santamarina, J.C., and Ruppel, C., 2008, Mechanical and electromagnetic properties of northern Gulf of Mexico sediments with and without hydrates: Marine Petroleum Geology, v. 25, p. 884-859.

Lee, M.W., 2002, Modified Biot-Gassmann theory for calculating elastic velocities for unconsolidated and consolidated sediments: Marine Geophysical Researches, v. 23, p. $403-412$.

Lee, M.W., 2005, Proposed moduli of dry rock and their application to predicting elastic velocities of sandstones: U.S. Geological Survey Scientific Investigations Report 2005-5119, 14 p.

Lee, M.W., 2006a, Inversion of elastic impedance for unconsolidated sediments: U.S. Geological Survey Scientific Investigations Report 2006-5081, 14 p.

Lee, M.W., 2006b, Explicit use of the Biot coefficient in predicting shear-wave velocity: Geophysical Prospecting, v. 54, p. $177-185$.

Lee, M.W., 2006c, A simple method of predicting S-wave velocity: Geophysics, v. 71, p. F161-F164.

Lee, M.W., and Collett, T.S., 2006, Gas hydrate and free gas saturations estimated from velocity logs on Hydrate Ridge, offshore Oregon, U.S.A., in Trehu, A.M., Bohrmann, G., Torres, M.E., and Colwell, F.S., eds., Proceedings of the Ocean Drilling Program Scientific Results, v. 204, 25 p., available at $h t t p: / / w w w-o d p . t a m u . e d u / p u b l i c a t i o n s / 204$ SR/103 /103.htm.

Milkov, A.V., and Sassen, R., 2001, Two-dimensional modeling of gas hydrate decomposition in the northwestern Gulf of Mexico-Significance to global change assessment: Global and Planetary Change, v. 36, p. 31-46.

Prasad, Manika, 2002, Acoustic measurements in unconsolidated sands at low effective pressure and overpressure detection: Geophysics, v. 67, p. 405-412. 
Pride, S.R., 2005, Relationship between seismic and hydrological properties, in Rubin, Y., and Hubbard, S., eds., Hydrogeophysics: New York, Kluwer Academy, p. 217-255.

Shedd, William, Hutchinson, D., Boswell, R., Collett, T., Dai, J., Dugan, B., Frye, M., Jones, E., McConnell, D., Rose, K., Ruppel, C., Shelander, D., and Wood, W., 2009, Gulf of Mexico Gas Hydrate Joint Industry Project Leg II-East Breaks 991 and Alaminos Canyon 21 site selection: Proceedings of the Drilling and Scientific Results of the 2009 Gulf of Mexico Gas Hydrate Joint Industry Project Leg II, $18 \mathrm{p}$.

Walton, K., 1987, The effective elastic moduli of a random packing of spheres: Journal of the Mechanics and Physics of Solids, v. 35, p. 213-226.

Xu, Shiyu, and White, R.E., 1996, A physical model for shearwave velocity prediction: Geophysical Prospecting, v. 44, p. 687-717.

Yun, T.S., Narsilio, G.A., and Santamarina, J.C., 2006, Physical characterization of core samples recovered from Gulf of Mexico: Marine and Petroleum Geology, v. 23. p. 893-900.

Zimmer, M.A., 2003, Seismic velocities in unconsolidated sands-Measurements of pressure, sorting, and compaction effects: Palo Alto, Calif., Stanford, Ph. D thesis 204 p.
Publishing support provided by:

Denver Publishing Service Center

For more information concerning this publication, contact: Center Director, USGS Central Energy Resources Science Center Box 25046, Mail Stop 939

Denver, CO 80225

(303) 236-1647

Or visit the Central Energy Resources Science Center Web site at: http://energy.cr.usgs.gov/ 